\title{
"Teaching:Individual" to Increase Adherence to Therapeutic Regimen in People with Hypertension and Type-2 Diabetes: Randomized Controlled Trial ENURSIN
}

Dora Inés Parra ( $\nabla$ doiparra@uis.edu.co)

Universidad Industrial de Santander https://orcid.org/0000-0003-1527-973X

Sandra Lucrecia Romero Guevara

Universidad Industrial de Santander

Lyda Zoraya Rojas Sánchez

Fundación Cardiovascular de Colombia

Research article

Keywords: Nursing Process, Diabetes Mellitus, Type 2, Hypertension, Patient Education as a Topic, Blood Pressure Monitoring, Ambulatory, Treatment Adherence and Compliance, Glycated Hemoglobin A.

Posted Date: December 5th, 2019

DOl: https://doi.org/10.21203/rs.2.18001/v1

License: (c) (1) This work is licensed under a Creative Commons Attribution 4.0 International License.

Read Full License 


\section{Abstract}

Background. Educational interventions with multifaceted approach have proven effective to improve adherence to the therapeutic regimen in people with chronic diseases. This study sought to evaluate the efficacy of the nursing intervention "Teaching: Individual" compared with usual care to increase adherence to therapeutic regimen and to analyze the impact of nursing interventions to decrease systolic blood pressure (SBP) and glycosylated hemoglobin ( $\mathrm{HbA1c}$ ) levels in people with hypertension and/or type-2 diabetes mellitus.

Methods. This was a two-arm parallel randomized clinical trial in 200 patients from primary care programs with arterial hypertension and type-2 diabetes. The intervention was designed with a multifaceted approach and conducted individually in six sessions. For statistical analysis of SBP, a linear marginal model was used with an exchangeable correlation matrix for repeated measures, and for treatment adherence as well as generalized $\mathrm{HbA} 1 \mathrm{c}$ estimating equations repeated measures were used with an unstructured correlation matrix, using all available data. All analyses were conducted in STATA software version 15.0 . Values of $p<0.05$ were considered statistically significant.

Results. After six months the follow up score adherence to the therapeutic regimen was higher in the "Teaching: Individual" group compared with the usual care group with a difference in the median of 0.87 points (95\% Cl: 0.30 to 1.44). The difference in the median of SBP between the groups was $-3.79 \mathrm{mmHg}$ ( $95 \% \mathrm{Cl}:-6.85$ to -0.73 ), in favor of the group intervened. The difference in the median of HbA1c was $-0.16 \%$ ( $95 \% \mathrm{Cl}:-0.41$ to 0.09 ). The effect was not maintained at 12 months of follow up in none of the variables of interest.

Conclusions. As well as in other contexts, this study determined that educational interventions with multifaceted approach leaded by nursing are effective in improving therapeutic adherence and control of tension figures in users of primary care programs with high blood pressure and type-2 diabetes. Trial Registration: ENURSIN was registered in ClinicalTrials.gov (NCT02758275) on 27 April 2016, protocol number 01. Keywords: Nursing Process; Diabetes Mellitus, Type 2; Hypertension, Patient Education as a Topic, Blood Pressure Monitoring, Ambulatory; Treatment Adherence and Compliance; Glycated Hemoglobin A.

\section{Background}

According to the 2014 report on the global situation of noncommunicable diseases, cardiovascular diseases (CVD) were the principal cause of death in 2012 and responsible for 17.5-million deaths (1). Hypertension, as one of the main causes of chronic cardiovascular conditions, caused 9.4-million deaths and $7 \%$ of the morbidity burden expressed in disability-adjusted life-years (DALYs) in 2010. For type-2 diabetes mellitus (DM2), it is calculated that approximately 4.0-million ( $95 \% \mathrm{Cl} 3.2$ to 5.0 ) people between 20 and 79 years of age would die from this condition in 2017 and is responsible for $10.7 \%$ of the global 
mortality (2). Both pathologies lead to severe complications, disabilities, death, and high costs in health care (3).

In spite of important progress in treating chronic diseases, like hypertension and DM2, lack adherence to the therapeutic regimen by patients remains a challenge for health systems and it has been evidenced that it is a barrier in controlling CVD (4). Different studies report prevalence of adherence to medication in patients with hypertension between $52 \%$ and $74 \%$ and in people with DM2 between $36 \%$ and $93 \%$ (5). Additionally, regarding non-pharmacological aspects, non-compliance has been reported for physical activity between $33.2 \%$ and $25 \%$ in diabetic patients $(6,7)$ and $68.8 \%$ in those who are hypertensive (8). Likewise, non-compliance with diet is reported between $88 \%$ and $44.8 \%$ in diabetics $(6,7)$ and $30.9 \%$ in the hypertensive (8). Consequently, unfavorable clinical results can be generated, such as rehospitalizations, exacerbations of other chronic diseases, and higher costs in medical care (9).

Within this context, different ways of measuring adherence to the therapeutic regimen have been proposed, however, most studies have focused on pharmacological aspects, leaving aside the integral approach of the recommendations for adequate control of chronic diseases, like recommendations of diet, physical activity, and control of other risk factors (smoking, obesity, among others) (10).

With respect to interventions to improve adherence to the therapeutic regimen, many of them have been found to have positive effects in controlling hypertension and DM2. Among these, emphasis has been made on educational interventions using various strategies with multifaceted approach, which have resulted most effective $(11,12)$. Likewise, the teach-back method has demonstrate effectiveness in a broad spectrum of results of medical care, evidencing better outcomes in disease-specific knowledge, adherence, self-efficacy among others (13). Similarly, interventions guided nurses and collaborative interventions between nursing and other members of the health staff have shown to improve moderately adherence in the elderly (9).

\section{Objectives}

In consideration with the aforementioned and seeking to rescue and guide the nurse's role in cardiovascular risk programs at national level and implement the most effective interventions in this area, a "Teaching: Individual" multifaceted intervention was designed by using different strategies to improve adherence to the therapeutic regimen both in the pharmacological and non-pharmacological treatments. The specific aims of the study were: 1 ) to evaluate the efficacy of nursing intervention "Teaching: Individual" (14) compared with usual care (control group), to increase adherence to therapeutic regimen in people with hypertension, DM2 or both; and 2) to analyze the impact of nursing interventions to decrease SBP and HbA1c levels in people with hypertension and DM2.

\section{Methods}

\section{Study Design}


This study was a single-blind, randomized clinical trial with a two-arm, parallel-group design. One group was given the "Teaching: Individual" intervention for six months, in addition to usual care and compared with a group that only received usual care; the follow-up was carried out over 12 months. The trial protocol was registered at ClinicalTrials.govunder registration numberNCT02758275 and published (15). The clinical trial was reported according to CONSORT guidelines (16).

\section{Participants and setting}

This trial was conducted from April 2016 to August 2017. Participants were recruited from programs for the control of cardiovascular risk factors in 21 primary care centers from the ESE-ISABU, Santander, Colombia. ESE-ISABU is a public health institution providing services with emphasis on primary care.

Eligibility criteria included being 18 years of age or older, medically diagnosed with hypertension, DM2 or both, being an active patient of programs for the control of cardiovascular risk factors of ESE-ISABU, being totally basic-care independent, having access to landline or mobile telephone and residing in Bucaramanga. Exclusion criteria involved showing mental spherechanges according to the Mini-Mental State Examination (MMSE) (17) and the Yesavage depression test (18); showing communication limitations, chronic or serious alterations that made comprehension of interventions difficult and subjects currently participating in a research study or who had done so in the previous six months.

To verify the inclusion criteria, a simple random sampling of the clinical histories of the population potentially eligible was carried out. Those who fulfilled the study criteria through clinical history were invited for a second verification of the inclusion criteria and application of the MMSE (17) and Yesavage depression testing (18). Finally, those meeting all the criteria were invited to participate in the study and those who accepted signed the informed consent.

\section{Sample size}

The research determined that 200 patients would be needed to provide the trial with $80 \%$ power to detect a minimal clinically important difference in the following parameters: mean $0.5 \pm 0.9$ points of adherence to treatment (Treatment Behavior: Illness or Injury); mean $10 \pm 21 \mathrm{mmHg}$ SBP levels in 24 hours, parameters determined in the researchers' preliminary work; mean $0.5 \% \pm 1.2$ difference in $\mathrm{HbA} 1 \mathrm{c}$ levels $(19,20)$ between the groups at 12 months, with the assumption of a two-tailed alpha level at $5.0 \%, 0.3$ average correlation between initial and final measurements, intervened group/control group ratio of 1:1, and $20 \%$ adjustment due to follow-up losses.

\section{Randomization and blinding}


Randomization was based on computer-generated random numbers prepared by an engineer, and an epidemiologist with not bearing in the trial conduct. Participants were allocated in a ratio of 1:1 to either the "Teaching: Individual" intervention or usual care group. Routine randomization for the study was developed as a function within a web application. This application is hosted on the Web servers of the structural Unit of Administration and Data Analysis (UAAD) at CARDIECOL. Users (nurses) entered the web platform via a browser and only those with the proper credentials could execute method randomization. This algorithm took as input parameters of each participant: informed consent, age, sex, diseases (hypertension, DM2, or both), as well as their identification code for stratification and, depending on the layer, they were assigned them to either intervention or control group. As soon as randomization results allocated each participant to a group, this information was displayed to the nurses who continued with the process. Nurses evaluated the outcomes, and the person conducting data analysis was blinded to group allocation (single blind).

\section{Interventions}

Participants in the intervention group received both usual care, and "Teaching: Individual" (14). The latter was defined as "Planning, implementation, and evaluation of a teaching program designed to address a patient's particular needs" (14). Patients were guided through the decision-making process, consisting of counseling sessions given by a trained nurse, one monthly educational session for six months.

The design of the intervention was of multifaceted nature, given that besides the pedagogic component, it also involved the behavioral and affective (12). As for the educational component, the intervention was designed to transmit information about the disease process, treatment, and control of risk factors, among others. The study used as strategies the "Teaching: Individual", written material, and devices to arrange medications and schedules, as well as delivery of stimuli related with each of the themes in the sessions.

As for the behavioral component, the intervention focused on changing unhealthy habits or reinforcing positive behaviors, thus, it included activities that allow patients to establish their own goals according to the therapeutic recommendations, likes, and resources, like for example, establishment of schedules to take medications, elaboration of menus and exercise routines, adjusted to individual needs.

With respect to the affective component, participants were urged to express feelings related with the experience of living with the disease and its treatment, identification of situations that generated personal or family discomfort, and the search for individual strategies related to family and social support.

The nurses delivered teachings about behavior modification, disease process, prescribed medication, prescribed diet, prescribed exercise, and coping enhancement. Most of the sessions lasted between 20 to 40 min, participants received their own educational material (booklet) with worksheets, pillbox, and a medication card. 
Participants in the control group received only usual care in the health center they attended for medical controls. The usual care interventions consisted of interdisciplinary management by the health staff providing care, according to the classification of the patient's CVD risk. Anamnesis, physical examination, prescribed medication treatment, education, control of modifiable factors (diet, physical activity, alcohol, tobacco, and adherence to treatment, among others), and laboratory and diagnosis tests are usually performed in medical controls. Most of these sessions lasted for 20 min.

\section{Outcomes and measures}

Participants were evaluated at baseline and approximately at 6 and 12 months of follow-up, respectively, for the intervention and control groups. Baseline questions assessed sociodemographic characteristics, health conditions, and outcomes through questionnaires, physical measurements, and blood testing. Baseline characteristics included age, sex, marital status, socioeconomic status, place of residence, schooling, occupation, pathology suffered, smoking status, weight, height, waist and hip circumference, and abbreviated Charlson index.

The following variables were taken from the medical records: total, high-density lipoprotein (HDL) and low-density lipoprotein (LDL) plasma cholesterol levels, plasma triglyceride levels, and prescribed medication. The primary outcome, change of mean of treatment adherence levels, was measured by selfreport of Treatment Behavior: Illness or Injury Questionnaire (21). The secondary outcomes consisted of the changes of mean in the SBP in 24 hours and HbA1c. The SBP, measured through ambulatory blood pressure monitoring (ABPM), using a WatchBP 03-microlife device; $\mathrm{HbA1c}$ was measured in peripheral venous blood, analyzed through immunoturbidimetry in whole blood by an accredited laboratory.

\section{Statistical analysis}

Analyses were based on intention to treat, where all participants remained in the allocated group, irrespective of compliance with the protocol. Summary statistics comparing randomized arms at baseline were tabulated: categorical and continuous variables were compared by chi-squared or Fisher exact tests and Student's t-test or Mann-Whitney U-test, respectively.

We modified the statistical analyses of outcomes approved in the protocol because it was basic analysis, and compensated for the losses that occurred during the follow-up. To use repeatedly measured data and investigate changes in an outcome over time and compare these changes among treatment groups, we used a linear marginal model with an exchangeable correlation matrix for repeated measures of SBP and generalized estimating equations (GEE) for repeated measures with an unstructured correlation matrix (treatment adherence and $\mathrm{HbA} 1 \mathrm{c})$, using all available data $(22,23)$. We used models predicting outcomes from treatment group, time, and the treatment group by time interaction. All analyses were conducted using STATA software version 15.0; $p$-values $<0.05$ were considered statistically significant. 
Sensitivity analyses were conducted. It is known from studies that the blood pressure measured at home or that found in practices without the presence of medical assistants is $10-15 \mathrm{mmHg}$ lower than the laboratory blood pressure measured in studies of medical assistants (24). Therefore, SBP was measured as automated office blood pressure (AOBP), using a WatchBP 03-microlife device in casual mode. Likewise, a sub-analysis was performed on SBP for 24 hours in participants with more than $70 \%$ correct measurements by ABPM, as recommended by the hypertension guidelines (25).

\section{Results}

\section{Participant Characteristics}

Participant recruitment and participation in the intervention took place from April 2016 through August 2017; 1286 participants were screened and 200 randomized, with 98 allocated to the "Teaching: Individual" group and 102 to the usual care group. Twenty-three participants refused to participate; the principal reason for not participating was their refusal to use the ABPM device. Their main sociodemographic and clinical characteristics were compared with the participants: $\operatorname{sex}(p=0.453)$, age $(p=0.049)$, socioeconomic status $(p=0.084)$, years of schooling $(p=0.184)$, diseases, hypertension, DM2 or both $(p=0.677)$, and adherence score $(p=0.704)$. The profile of these characteristics was similar in the participants and non-participants, except for age, which was statistically different, showing a mean-age difference of 4.8 years (mean age of $62.8 \pm 11.1$ years in participants vs. $67.6 \pm 9.82$ years in non-participants). One hundred eighty-six participants (93.0\%) completed the 12-month follow-up visit and were included in the analysis; $96.5 \%$ adherence scoreprimary outcome), $84.8 \%$ SBP in 24 hours (second outcome) and $96.2 \%$ for $\mathrm{HbA}_{1 \mathrm{c}}$ (third outcome) (Figure 1).

The mean (SD) age of participants was $62.8 \pm 11.1$ years and most were women $73.0 \%$ [ $n=146], 49.0 \%$ [n $=98]$ were married or living in common-law union, $87.0 \%[n=174]$ were from low socioeconomic status, $58.5 \%[n=117]$ were housewives, $62.5 \%[n=125]$ were diagnosed with hypertension, $12.0 \%[n=24]$ had $\mathrm{DM} 2$, and $25.5 \%$ [ $\mathrm{n}=51]$ had both conditions. Participants had a mean (SD) adherence score of $9.39 \pm 2.05$ points, SBP in $24 \mathrm{~h}$ at $124 \pm 14.3 \mathrm{mmHg}, \mathrm{HbA} 1 \mathrm{c}$ at $6.18 \pm 1.58 \%$, SBP (AOBP) of $136 \pm 19.5$ $\mathrm{mmHg}$, and SBP in $24 \mathrm{~h}$ (70\% correct measurements) of $124 \pm 14.0 \mathrm{mmHg}$. Baseline characteristics of participants are shown in Table 1. These were totally balanced between groups $(p>0.05)$.

\section{Outcomes}

\section{Primary outcome}

Mean (SE) adherence score change at six months was $10.73(0.20)$ points in the teaching: individual group and $9.86(0.20)$ in the usual care group, and at 12 months it was $10.43(0.21)$ vs. $10.03(0.20)$ (Figure 2, A). The difference in mean adherence score change at 6 months was greater in the "Teaching: 
Individual" group compared with usual care (mean difference, 0.87 points; $95 \% \mathrm{Cl}, 0.30$ to $1.44 ; p=$ 0.003). In addition, adherence score at 12 months was higher in the "teaching: individual" group compared with usual care; however, this difference was no statistically significant (mean difference, 0.39 points; $95 \% \mathrm{Cl},-0.21$ to $0.99 ; p=0.199$ ) (Table 2 ).

\section{Secondary outcomes}

Mean (SE) SBP ABPM change at 6 months was $122(1.51) \mathrm{mmHg}$ in the teaching: individual group and $124(1.48) \mathrm{mmHg}$ in the usual care group, and at 12 months was 121 (1.77) vs. 120 (1.63) (Figure 2, $B$ ).Mean SBP at six months decreased between the "Teaching: Individual" group and usual care (mean difference of $-3.79 \mathrm{mmHg} ; 95 \% \mathrm{Cl},-6.85$ to $-0.73 ; p=0.015)$, but the effect of the "Teaching: Individual" group on SBP at 12 months was not significant (mean difference of $-0.31 \mathrm{mmHg} ; 95 \% \mathrm{Cl},-3.69$ to 3.08; $p=0.858$ ) (Table 2). Mean $\mathrm{HbA}_{1 \mathrm{c}}$ decreased at 6 and 12 months follow up between the "Teaching: Individual" group and usual care, but these were not significant (mean difference of $-0.16 \% ; 95 \% \mathrm{Cl}$, 0.41 to $0.09 ; p=0.213$ ), and (mean difference, $-0.06 \% ; 95 \% \mathrm{Cl},-0.32$ to $0.19 ; p=0.618$ ), respectively (Figure 2, Cand Table 2).

\section{Sensitivity analysis}

Mean (SE) SBP AOBP change at six months was 128 (2.23) points in the "Teaching: Individual" group and 135 (2.16) in the usual care group, and at 12 months it was 130 (2.62) vs. 134 (2.38) (Figure 3, A). The difference in mean SBP AOBP change at six months decreased in the "Teaching: Individual" group compared with usual care (mean difference of $-7.49 \mathrm{mmHg} ; 95 \% \mathrm{Cl},-13.76$ to $-1.22 ; p=0.019$ ). Also, SBP AOBP at 12 months decreased in the "Teaching: Individual" group compared with usual care; however, this difference was not statistically significant (mean difference of $-3.27 \mathrm{mmHg} ; 95 \% \mathrm{Cl}$, 10.18 to $3.65 ; p=0.353$ ) (Table 2).

Similarly, mean (SE) SBP in 24 hours ABPM in participants with more than $70 \%$ correct measurements at six months was 122 (1.55) points in the "Teaching: Individual" group and 124 (1.50) in the usual care group, and at 12 months it was 122 (1.80) vs. 121 (1.67) (Figure 3, B). The difference in mean SBP change in 24 hours at six months decreased in the "Teaching: Individual" group compared with usual care (mean difference of $-4.58 \mathrm{mmHg} ; 95 \% \mathrm{Cl},-7.79$ to $-1.37 ; p=0.005$ ), and at 12 months (mean difference of $-0.90 \mathrm{mmHg} ; 95 \% \mathrm{Cl},-4.43$ to $2.63 ; p=0.616$ ) (Table 2).

\section{Discussions}

Although at the beginning of the study the participants had results variables within normal parameters (controlled), this research evidenced that the nursing intervention "Teaching: Individual", using different strategies, like those used in this study, achieved increased adherence to treatment and a significant 
reduction of SBP in 24 hours, both ABPM and AOBP, at 6-month follow up; however, these were not significant at 12 months, nor were they significant for HbA1c during any of the follow-up times.

Ours was a multifaceted intervention, involving different adherence aspects; additionally, it was conducted only by nursing professionals, individually, face-to-face with each of the participants from the intervention group. Considering these aspects on the outcomes of interest, our results are consistent with findings from other recent studies. For example, a systematic review of interventions on adherence to anti-diabetic medications in patients with DM2 determined that multifaceted interventions, approaching various factors of non-adherence to medication, were more effective to improve compliance with the pharmaceutical regimen and achieve glycemic target compared with single-component strategies (12).

Likewise, the systematic review by Verloo $\mathrm{H}$ et al.,, which evaluated the effect of nursing interventions to improve adherence to medication for the elderly living at home and who were discharged, established that interventions guided by nurses and those collaborative with the nursing staff improved moderately adherence among the elderly (9). The systematic review by Ha Dinh TT et al.,, supported by the teachback method to maximize comprehension of the disease, promote knowledge, adherence, self-efficacy, and self-care skills on educating people with chronic diseases (13).

Regarding the effect on blood pressure, our study found similar results to those reported in a systematic review that evidenced that interventions aimed at patients, with multiple and motivational educational sessions to modify lifestyles and adherence to medication, obtained a mean change in SBP of -3.9 $\mathrm{mmHg}(95 \% \mathrm{Cl}:-5.4$ to -2.3$)$ (26). In addition, it has been shown that interventions designed to decrease blood pressure that support usual medical care, where only Nursing participates or together with other members not belonging to the medical staff, are effective to achieve control of blood pressure, however, it is important to highlight that greater effectiveness was found when the interventions are multidisciplinary; with average effects of $-7.1 \mathrm{mmHg}(95 \% \mathrm{Cl}:-8.9$ to -5.2$)(26,27)$.

In relation with the effect of educational interventions on decreasing HbA1c levels, upon examining results from systematic reviews and meta-analyses, divergent results were found, thus, a review of 118 studies found significant changes in only $61.9 \%$ in diminished $\mathrm{HbA} 1 \mathrm{c}$. In the same review, the mean general reduction for $\mathrm{HbA} 1 \mathrm{c}$ was at $0.74 \%( \pm 0.63)$ with a range from 0.6 to $-2.50(28)$. Additionally, as in our study, a meta-analysis of eight randomized clinical trials (RCT) found no significant changes in the means of $\mathrm{HbA} 1 \mathrm{c}$ between the participants in the educational intervention and the usual care with differences of $-0.08 \%$ (95\% Cl: -0.40 to 0.23$)$ (29) and, contrary to our results, a meta-analysis of $13 \mathrm{RCT}$ found significant $\mathrm{HbA} 1 \mathrm{c}$ reduction of $-0.25 \%(95 \% \mathrm{Cl}:-0.42$ to -0.07$)$, in favor of the intervention group(30).

An important aspect that must be analyzed is the base value of the HbA1c levels, in consideration of participants in our study had means levels within control range and when reviewing the scientific literature, it has been noted that most studies were conducted in people with poor glycemic control, where a greater benefit is expected from the educational interventions for self-control of diabetes and, consequently, decreased HbA1c levels $(28,29)$. 
Furthermore, it has been determined that educational interventions are more effective when offered by the interdisciplinary staff compared with a single provider and, regarding the way of providing them, individualized interventions are more effective than group interventions, but combined interventions have greater effect $(28,29)$.

\section{Study limitations and strengths}

The strong points of our research include being a controlled randomized clinical trial that uses a multifaceted educational intervention compared with usual care. Desertion rate was below that estimated $(<20 \%)$; sociodemographic and clinical characteristics of the groups at the beginning of the study were statistically similar, which indicates that the random assignment procedure was robust; SBP was measured objectively by using ABPM as a more reliable and accurate measure; finally, advanced statistical methods were used for data analysis.

Although our results were positive for two outcomes at six months of follow up, we recognize the following limitations related with this study. The clinical trial was parallel type, hence, we do not discard contamination of the study as a result of physicians in the usual care treating patients in both arms of the study, which could have been avoided with cluster design; likewise, we do not discard the Hawthorneeffect that implies a modification in some aspect of their behavior as consequence of their knowing that they are being studied, and not in response to some type of manipulation contemplated in the intervention (31). The means of the outcomes were within optimal levels in the baseline, which is why it was difficult to achieve significant changes at 12 months of follow up, especially in HbA1c levels, whereaccording to the literature-changes are achieved in patients with $\mathrm{HbA1c} \geq 7 \%$ (32). In turn, it is likely that the study did not have the adequate power to detect the calculated delta difference of SBP and HbA1C between the groups at 12 months of follow up. No documentation was made of the timely delivery of pharmacological treatment by the health system during follow up, an aspect that is crucial to control the disease. Additionally, the variety of instruments used to measure adherence constitutes a limitation, in addition to most of them centering only on pharmacological compliance, leaving aside the other key components in measuring adherence, aspects that hinder the comparison of our findings.

\section{Implications to Clinical Practice and Future Research}

This study suggests that the "Teaching: Individual" intervention with multifaceted approach conducted by nurses can be effective to improve therapeutic adherence and control of SBP in hypertensive and/or diabetic individuals involved with cardiovascular risk programs in the region's public sector, when the intervention is maintained over time. Although minimum changes were evidenced for $\mathrm{HbA} 1 \mathrm{c}$, these differences were not statistically significant at six and 12 months of follow up, therefore further studies are needed that included uncontrolled patients, with $\mathrm{HbA} 1 \mathrm{c}$ values above the control range. 
Moreover, given that the intervention addresses the different recommendations (diet, physical activity, and pharmacological treatment among others) suggested by clinical management guides for hypertension and diabetes, these could be enhanced by other members of the interdisciplinary team, like the physician in the pharmacological treatment, the dietician in the diet component, and the physical therapist in the exercise part, among others, meaning that in the long term this intervention can be incorporated as a daily practice procedure in comprehensive care to people with cardiovascular risk factors, which is coherent with that currently contemplated by the Comprehensive Health Model in Colombia (MIAS)(33).

\section{Abbreviations}

CARDIECOL: Conocimiento y Acción para Reducir la Dimensión de la Enfermedad Cardiovascular en Colombia (Knowledge and Action to Reduce the Dimension of Cardiovascular Disease in Colombia)

ISABU: Instituto de Salud de Bucaramanga

ENURSIN (Educational Nursing Interventions)

\section{Declarations}

\section{Ethics approval and consent to participate}

This study was deemed of minimal risk and was approved by two ethics committees: The Ethics Committee in Scientific Research at Universidad Industrial de Santander (CEINCI-UIS), entity responsible for the project, on 27 October 2015, and the Research Ethics Committee at ESE ISABU, entity where the study was conducted, on 21 October 2015.

The objectives, importance, risks, and benefits of the research and data confidentiality were explained to all participants before recruitment and a nurse obtained written informed consent from them.

At the end of the study, the participants of the control group also received the educational sessions, the educational material (booklet), the pillbox and the medication card delivered to the intervention group. In addition, the nurses of the E. S.E ISABU care centers were trained in the topics that included the educational material used in the intervention as part of the commitments made with the primary care center.

\section{Consent for publication}

Not applicable

\section{Availability of data and materials}


We cannot publicly share the data due to participant confidentiality reasons, but in case these are requested for verification or confirmation of the study's findings, such will be provided with prior written request indicating the mechanisms that will guarantee confidentiality in the use of participant data.

\section{Competing interests}

Authors SLR, DIP, LZR declare having no competing interests

\section{Funding}

This project was part of the temporary union CARDIECOL, an alliance comprising several institutions, among them, Universidad Industrial de Santander.

This project was funded by COLCIENCIAS CT: 696-2014, code: 617399847755 and Universidad Industrial de Santander code 617399847755 . These institutions funded all ENURSIN trial costs. The funding source had no role in the design of this study and had no role during its execution, analysis, data interpretation, or decision to submit results.

\section{Authors' contributions}

The study was carried out in collaboration among the authors. SLR and LZR were involved in the study design. DIP and SLR were involved in the planning, coordination, and management of data acquisition at the study site. LZR contributed to the statistical planning of the study and wrote the first manuscript draft. DIP and SLR substantially contributed to the manuscript draft. DIP and SLR critically revised the manuscript. SLR and DIP conceived the study and applied for funding. All authors read and approved the final version of the manuscript.

\section{Acknowledgements}

We thank ESE-ISABU for its support in granting space for measurements and intervention, as well as in access to patient information in the Cardiovascular Risk Program.

We also thank CARDIECOL's management staff for their support with conducting the project, as well as its UAAD for their valuable support regarding the web design for data collection and randomization of patients.

\section{References}


1.World Health Organization. Global status report on noncommunicable diseases 2014. In: WHO, editor. "Attaining the nine global noncommunicable diseases targets; a shared responsibility". Geneva 2014.

2.International Diabetes Federation. IDF Diabetes Atlas. Brussels, Belgium 2017. Available from: https://diabetesatlas.org/.

3.Buffel du Vaure C, Ravaud P, Baron G, Barnes C, Gilberg S, Boutron I. Potential workload in applying clinical practice guidelines for patients with chronic conditions and multimorbidity: a systematic analysis. BMJ Open. 2016;6(3):e010119-e.

4.Ministério da Saúde do Brasil. Síntese de evidências para políticas de saúde: adesão ao tratamento medicamentoso por pacientes portadores. In: Departamento de Ciência e Tecnologia, editor. Brasília-DF: EVIPNet; 2016. p. 54.

5.Chang PY, Chien LN, Lin YF, Chiou HY, Chiu WT. Nonadherence of Oral Antihyperglycemic Medication Will Increase Risk of End-Stage Renal Disease. Medicine. 2015;94(47):e2051. Epub 2015/12/04.

6.Saleh F, Mumu SJ, Ara F, Hafez MA, Ali L. Non-adherence to self-care practices \& medication and health related quality of life among patients with type-2 diabetes: a cross-sectional study. BMC public health. 2014;14(1):431. Epub 2014/06/03.

7.Mumu SJ, Saleh F, Ara F, Afnan F, Ali L. Non-adherence to lifestyle modification and its factors among type 2 diabetic patients. Indian journal of public health. 2014;58(1):40-4.

8.Tibebu A, Mengistu D, Negesa L. Adherence to recommended lifestyle modifications and factors associated for hypertensive patients attending chronic follow-up units of selected public hospitals in Addis Ababa, Ethiopia. Patient preference and adherence. 2017;11:323-30.

9.Verloo H, Chiolero A, Kiszio B, Kampel T, Santschi V. Nurse interventions to improve medication adherence among discharged older adults: a systematic review. Age and Ageing. 2017;46(5):747-54.

10.López Romero LA, Romero Guevara SL, Parra DI, LZ. RS. Adherencia al tratamiento: Concepto y medición. Hacia promoc salud. 2016;21(1):117-37.

11.Conn VS, Ruppar TM, Chase J-AD, Enriquez M, Cooper PS. Interventions to Improve Medication Adherence in Hypertensive Patients: Systematic Review and Meta-analysis. Current hypertension reports. 2015;17(12):94-.

12.Sapkota S, Brien J-A, Greenfield J, Aslani P. A Systematic Review of Interventions Addressing Adherence to Anti-Diabetic Medications in Patients with Type-2 Diabetes-Components of Interventions. PLoSONE. 2015;10(6):0128581.

13. Ha Dinh TT, Bonner A, Clark R, Ramsbotham J, Hines S. The effectiveness of the teach-back method on adherence and self-management in health education for people with chronic disease: a systematic 
review. JBI Database System Rev Implement Rep. 2016;14(1):210-47.

14.Bulechek GM, Butcher HK, Dochterman JM, Wagner C. Nursing Interventions Classification (NIC). Sixth ed2012.

15.Romero Guevara SL, Parra DI, Rojas LZ. "Teaching: Individual" to increase adherence to therapeutic regimen in people with hypertension and type-2 diabetes: protocol of the controlled clinical trial ENURSIN. BMC Nursing. 2019;18(1):22.

16.Schulz KF, Altman DG, Moher D, the CG. CONSORT 2010 Statement: updated guidelines for reporting parallel group randomised trials. BMC Medicine. 2010;8(1):18.

17.Rosselli D, Ardila A, Pradilla G, Morillo L, Bautista L, Rey O, et al. [The Mini-Mental State Examination as a selected diagnostic test for dementia: a Colombian population study. GENECO]. Revista de neurologia. 2000;30(5):428-32. Epub 2000/04/25. El examen mental abreviado (Mini-Mental State Examination) como prueba de seleccion para el diagnostico de demencia: estudio poblacional colombiano. GENECO.

18.Bacca A, González A, Uribe AF. Validación de la escala de depresión de Yesavage (versión reducida) en adultos mayores colombianos. Pensamiento Psicológico. 2005;1(5):53-63.

19.Crowley MJ, Powers BJ, Olsen MK, Grubber JM, Koropchak C, Rose CM, et al. The Cholesterol, Hypertension, And Glucose Education (CHANGE) study: results from a randomized controlled trial in African Americans with diabetes. American heart journal. 2013;166(1):179-86. Epub 2013/07/03.

20. Heisler M, Vijan S, Makki F, Piette JD. Diabetes control with reciprocal peer support versus nurse care management: a randomized trial. Annals of internal medicine. 2010;153(8):507-15. Epub 2010/10/20.

21.Moorhead S, Johnson M, Meridean M, E. S. Nursing Outcomes Classification (NOC). $4^{\text {th }}$ ed: ELSEVIER 2008.

22.Ma Y, Mazumdar M, Memtsoudis SG. Beyond repeated-measures analysis of variance: advanced statistical methods for the analysis of longitudinal data in anesthesia research. Reg Anesth Pain Med. 2012;37(1):99-105.

23.Albert PS. Longitudinal data analysis (repeated measures) in clinical trials. Stat Med. 1999;18(13):1707-32.

24.Myers MG, Godwin M, Dawes M, Kiss A, Tobe SW, Kaczorowski J. The conventional versus automated measurement of blood pressure in the office (CAMBO) trial: masked hypertension sub-study. J Hypertens. 2012;30(10):1937-41.

25.Williams B, Mancia G, Spiering W, Agabiti Rosei E, Azizi M, Burnier M, et al. 2018 ESC/ESH Guidelines for the management of arterial hypertension. Eur Heart J. 2018;39(33):3021-104. 
26.Mills KT, Obst KM, Shen W, Molina S, Zhang H-J, He H, et al. Comparative Effectiveness of Implementation Strategies for Blood Pressure Control in Hypertensive Patients: A Systematic Review and Meta-analysis. Annals of internal medicine. 2018;168(2):110-20.

27.Clark CE, Smith LFP, Taylor RS, Campbell JL. Nurse-led interventions to improve control of blood pressure in people with hypertension: systematic review and meta-analysis. BMJ (Clinical research ed). 2010;341:c3995-c.

28.Chrvala CA, Sherr D, Lipman RD. Diabetes self-management education for adults with type-2 diabetes mellitus: A systematic review of the effect on glycemic control. Patient education and counseling. 2016;99(6):926-43.

29.Cunningham AT, Crittendon DR, White N, Mills GD, Diaz V, LaNoue MD. The effect of diabetes selfmanagement education on $\mathrm{HbA} 1 \mathrm{c}$ and quality of life in African-Americans: a systematic review and metaanalysis. BMC Health Services Research. 2018;18(1):367.

30.Ferguson S, Swan M, Smaldone A. Does Diabetes Self-management Education in Conjunction with Primary Care Improve Glycemic Control in Hispanic Patients?: A Systematic Review and Meta-analysis. The Diabetes Educator. 2015;41(4):472-84.

31.Sharpe S, Kool B, Whittaker R, Ameratunga S. Hawthorne effect in the YourCall trial suggested by participants' qualitative responses. Journal of clinical epidemiology. 2019:1-3.

32. Wolever RQ, Dreusicke M, Fikkan J, Hawkins TV, Yeung S, Wakefield J, et al. Integrative Health Coaching for Patients with Type-2 Diabetes. The Diabetes Educator. 2010;36(4):629-39.

33.Ministerio de Salud y Protección Social de Colombia. Politíca de atención integral en salud "Un sistema de salud al servicio de la gente". In: Imprenta Nacional de Colombia editor. Bogotá D.C.2016. p. 97.

\section{Tables}

Table 1. Baseline characteristics of participants assigned to Teaching: Individual group or Usual Care. 


\begin{tabular}{|c|c|c|c|c|}
\hline \multirow[b]{2}{*}{ Characteristics } & \multirow[b]{2}{*}{$\begin{array}{c}\text { Total } \\
(\mathrm{n}=200)\end{array}$} & \multicolumn{2}{|c|}{ Study Group } & \multirow[b]{2}{*}{$\begin{array}{c}\text { p- } \\
\text { value }\end{array}$} \\
\hline & & $\begin{array}{l}\text { Teaching: Individual } \\
(\mathrm{n}=98)\end{array}$ & $\begin{array}{l}\text { Usual Care } \\
(\mathrm{n}=102)\end{array}$ & \\
\hline \multicolumn{5}{|l|}{ Sociodemographic } \\
\hline Age (years) & $62.8 \pm 11.1$ & $62.8 \pm 11.6$ & $62.7 \pm 10.7$ & 0.948 \\
\hline \multicolumn{5}{|l|}{ Sex } \\
\hline Women & $146(73.00)$ & $72(73.47)$ & $74(72.55)$ & \multirow[t]{2}{*}{0.883} \\
\hline Men & $54(27.00)$ & $26(26.53)$ & $28(27.45)$ & \\
\hline \multicolumn{5}{|l|}{ Marital status } \\
\hline Married/living in common-law union & $98(49.00)$ & $50(51.02)$ & $48(47.06)$ & \multirow[t]{4}{*}{0.950} \\
\hline Divorced & $19(9.50)$ & $9(9.18)$ & $10(9.80)$ & \\
\hline Single & $48(24.00)$ & $23(23.47)$ & $25(24.51)$ & \\
\hline Widowed & $35(17.50)$ & $16(16.33)$ & $19(18.63)$ & \\
\hline \multicolumn{5}{|l|}{ Socioeconomic status } \\
\hline Low & $174(87.00)$ & $84(85.71)$ & $90(88.24)$ & \multirow[t]{2}{*}{0.596} \\
\hline Medium & $26(13.00)$ & $14(14.29)$ & $12(11.76)$ & \\
\hline Years of schooling & $5(2-5)$ & $4(2-5)$ & $5(2-5)$ & 0.443 \\
\hline \multicolumn{5}{|l|}{ Occupation } \\
\hline Unemployed & $22(11.00)$ & $9(9.18)$ & $13(12.75)$ & \multirow[t]{5}{*}{0.455} \\
\hline Employed & $13(6.50)$ & $4(4.08)$ & $9(8.82)$ & \\
\hline Housewives & $117(58.50)$ & $60(61.22)$ & $57(55.88)$ & \\
\hline Independent & $47(23.50)$ & $24(24.49)$ & $23(22.55)$ & \\
\hline Pensioners & $1(0.50)$ & $1(1.02)$ & $0(0.00)$ & \\
\hline \multicolumn{5}{|l|}{ Health care center } \\
\hline - & $7(3.50)$ & $3(3.06)$ & $4(3.92)$ & \multirow[t]{20}{*}{0.771} \\
\hline 2 & $6(3.00)$ & $3(3.06)$ & $3(2.94)$ & \\
\hline 3 & $3(1.50)$ & $0(0.00)$ & $3(2.94)$ & \\
\hline 4 & $3(1.50)$ & $2(2.04)$ & $1(0.98)$ & \\
\hline 5 & $6(3.00)$ & $3(3.06)$ & $3(2.94)$ & \\
\hline 6 & $2(1.00)$ & $1(1.02)$ & $1(0.98)$ & \\
\hline 7 & $11(5.50)$ & $3(3.06)$ & $8(7.84)$ & \\
\hline 8 & $31(15.50)$ & $18(18.37)$ & $13(12.75)$ & \\
\hline 9 & $10(5.00)$ & $3(3.06)$ & $7(6.86)$ & \\
\hline 10 & $4(2.00)$ & $4(4.08)$ & $0(0.00)$ & \\
\hline 11 & $6(3.00)$ & $3(3.06)$ & $3(2.94)$ & \\
\hline 12 & $6(3.00)$ & $3(3.06)$ & $3(2.94)$ & \\
\hline 13 & $4(2.00)$ & $1(1.02)$ & $3(2.94)$ & \\
\hline 14 & $24(12.00)$ & $14(14.29)$ & $10(9.80)$ & \\
\hline 15 & $12(6.00)$ & $6(6.12)$ & $6(5.88)$ & \\
\hline 16 & $22(11.00)$ & $11(11.22)$ & $11(10.78)$ & \\
\hline 17 & $2(1.00)$ & $1(1.02)$ & $1(0.98)$ & \\
\hline 18 & $3(1.50)$ & $1(1.02)$ & $2(1.96)$ & \\
\hline 19 & $13(6.50)$ & 7 (7.14) & $6(5.88)$ & \\
\hline 20 & $25(12.50)$ & $11(11.22)$ & $14(13.73)$ & \\
\hline \multicolumn{5}{|l|}{ Clinics } \\
\hline Diseases & & & & \\
\hline Type-2 diabetes & $24(12.00)$ & $11(11.22)$ & $13(12.75)$ & \multirow{3}{*}{0.944} \\
\hline Hypertension & $125(62.50)$ & $62(63.27)$ & $63(61.76)$ & \\
\hline Hypertension/Type-2 diabetes & $51(25.50)$ & $25(25.51)$ & $26(25.49)$ & \\
\hline Charlson index (points) & $1(0-1)$ & $1(0-1)$ & $1(0-1)$ & 0.913 \\
\hline Tobacco consumption in the last year & $12(6.15)$ & $6(6.25)$ & $6(6.06)$ & 0.956 \\
\hline Body mass index $\left(\mathrm{kg} / \mathrm{m}^{2}\right)$ & $29.1 \pm 5.4$ & $29.5 \pm 5.5$ & $28.7 \pm 5.3$ & 0.349 \\
\hline Waist-hip index & $0.89 \pm 0.07$ & $0.90 \pm 0.07$ & $0.89 \pm 0.08$ & 0.440 \\
\hline \multicolumn{5}{|l|}{ Cholesterol (mg/dl) } \\
\hline Total & $196 \pm 40$ & $200 \pm 34$ & $192 \pm 45$ & 0.165 \\
\hline Low-density lipoprotein (LDL) & $114 \pm 37$ & $118 \pm 36$ & $111 \pm 38$ & 0.248 \\
\hline
\end{tabular}




\begin{tabular}{|l|c|c|c|c|} 
High-density lipoprotein (HDL) & $48 \pm 12$ & $48 \pm 12$ & $48 \pm 11$ & 0.838 \\
\hline Triglycerides & $173 \pm 84$ & $165(115-204)$ & $152(116-207)$ & 0.257 \\
\hline Pharmacological treatment & & & & \\
\hline $\begin{array}{l}\text { Angiotensin-converting enzyme } \\
\text { inhibitor }\end{array}$ & $29(14.50)$ & $13(13.27)$ & $16(15.69)$ & 0.627 \\
\hline Blockers & $45(22.50)$ & $23(23.47)$ & $22(21.57)$ & 0.748 \\
\hline Angiotensin receptor blocker & $124(62.00)$ & $58(59.18)$ & $66(64.71)$ & 0.421 \\
\hline Calcium antagonists & $50(25.00)$ & $27(27.55)$ & $23(22.55)$ & 0.414 \\
\hline Aldosterone antagonist & $6(3.00)$ & $3(3.06)$ & $3(2.94)$ & 0.640 \\
\hline Diuretic & $81(40.50)$ & $43(43.88)$ & $38(37.25)$ & 0.340 \\
\hline Digoxin & $2(1.00)$ & $1(1.02)$ & $1(0.98)$ & 0.741 \\
\hline Hypoglycemic & $69(34.50)$ & $33(33.67)$ & $36(35.29)$ & 0.810 \\
\hline Lipid lowering & $61(30.50)$ & $36(36.73)$ & $25(24.51)$ & 0.060 \\
\hline Anti-platelet & $106(53.00)$ & $54(55.10)$ & $52(50.98)$ & 0.559 \\
\hline Anticoagulants & $2(1.00)$ & $2(2.04)$ & $0(0.00)$ & 0.239 \\
\hline Outcomes & & & & 0.957 \\
\hline Adherence score (points) & $9.39 \pm 2.05$ & $9.39 \pm 1.97$ & $9.38 \pm 2.13$ & 0.957 \\
\hline SBP in 24 hours (mmHg) & $124 \pm 14.3$ & $125 \pm 14.6$ & $123 \pm 13.9$ & 0.385 \\
\hline HbA1c (\%) & $6.18 \pm 1.58$ & $6.19 \pm 1.71$ & $6.15 \pm 1.44$ & 0.879 \\
\hline SBP AOBP (mmHg) & $136 \pm 19.5$ & $136 \pm 19.9$ & $135 \pm 19.1$ & 0.775 \\
\hline SBP in 24 hours (mmHg) & $124 \pm 14.0$ & $125 \pm 14.2$ & $123 \pm 13.7$ & 0.292 \\
\hline
\end{tabular}

This table contains $\mathrm{n}$ (\%) for categorical variables and mean (standard deviation) or median (first and third quartile) for continuous variables. $*=$ Systolic blood pressure in $24 \mathrm{~h}$ in participants with more than $70 \%$ correct measurements in ambulatory blood pressure monitoring (ABPM).

Abbreviations: SBP: Systolic blood pressure, ambulatory blood pressure monitoring; AOBP: Automated office blood pressure; HbA1c=Glycated hemoglobin.

Table 2. Treatment effect on adherence, SBP, and HbA1c in individuals with hypertension and/or diabetes mellitus. 


\begin{tabular}{|c|c|c|c|c|c|c|c|c|c|c|}
\hline \multirow[b]{3}{*}{$\begin{array}{l}\text { Outcomes } \\
\text { Mean (SE) }\end{array}$} & \multicolumn{3}{|c|}{ Teaching: individual } & \multicolumn{3}{|c|}{ Usual Care } & \multicolumn{4}{|c|}{ Treatment Comparison } \\
\hline & \multirow[b]{2}{*}{ Baseline } & \multirow[b]{2}{*}{$6 \mathrm{mo}$} & \multirow[b]{2}{*}{$12 \mathrm{mo}$} & \multirow[b]{2}{*}{ Baseline } & \multirow[b]{2}{*}{$6 \mathrm{mo}$} & \multirow[b]{2}{*}{$12 \mathrm{mo}$} & \multicolumn{2}{|l|}{$6 \mathrm{mo}$} & \multicolumn{2}{|c|}{$12 \mathrm{mo}$} \\
\hline & & & & & & & $\begin{array}{c}\text { Difference } \\
95 \% \text { CI v }\end{array}$ & $\begin{array}{l}\text { p- } \\
\text { alue }\end{array}$ & $\begin{array}{c}\text { Difference } \\
95 \% \text { CI v }\end{array}$ & $\begin{array}{c}\mathrm{p}- \\
\text { alue }\end{array}$ \\
\hline $\begin{array}{l}\text { Adherence } \\
\text { score } \\
\text { (points) }\end{array}$ & $\begin{array}{c}9.40 \\
(0.20)\end{array}$ & $\begin{array}{l}10.73 \\
(0.20)\end{array}$ & $\begin{array}{l}10.43 \\
(0.21)\end{array}$ & $\begin{array}{c}9.38 \\
(0.19)\end{array}$ & $\begin{array}{c}9.86 \\
(0.20)\end{array}$ & $\begin{array}{l}10.03 \\
(0.20)\end{array}$ & $\begin{array}{c}0.87 \\
(0.30 \text { to } \\
1.44)^{\mathrm{b}}\end{array}$ & 0.003 & $\begin{array}{c}0.39 \\
(-0.21 \text { to } \\
0.99)^{b}\end{array}$ & 0.199 \\
\hline $\begin{array}{l}\text { SBP in } 24 \\
\text { hours } \\
\text { (mmHg) } \\
\text { ABPM }\end{array}$ & $\begin{array}{c}125 \\
(1.41)\end{array}$ & $\begin{array}{c}122 \\
(1.51)\end{array}$ & $\begin{array}{c}121 \\
(1.77)\end{array}$ & $\begin{array}{c}123 \\
(1.38)\end{array}$ & $\begin{array}{c}124 \\
(1.48)\end{array}$ & $\begin{array}{c}120 \\
(1.63)\end{array}$ & $\begin{array}{c}-3.79 \\
(-6.85 \text { to } \\
-0.73)^{C}\end{array}$ & 0.015 & $\begin{array}{c}-0.31 \\
(-3.69 \text { to } \\
3.08)^{\mathrm{C}}\end{array}$ & 0.858 \\
\hline HbA1c (\%) & $\begin{array}{c}6.19 \\
(0.16)\end{array}$ & $\begin{array}{c}6.16 \\
(0.16)\end{array}$ & $\begin{array}{c}6.19 \\
(0.16)\end{array}$ & $\begin{array}{c}6.16 \\
(0.15)\end{array}$ & $\begin{array}{c}6.27 \\
(0.16)\end{array}$ & $\begin{array}{c}6.26 \\
(0.16)\end{array}$ & $\begin{array}{c}-0.16 \\
(-0.41 \text { to } \\
0.09)^{b}\end{array}$ & 0.213 & $\begin{array}{c}-0.06 \\
(-0.32 \text { to } \\
0.19)^{b}\end{array}$ & 0.618 \\
\hline $\begin{array}{l}\text { Sensitivity } \\
\text { analysis }\end{array}$ & Baseline & $6 \mathrm{mo}$ & $12 \mathrm{mo}$ & Baseline & $6 \mathrm{mo}$ & $12 \mathrm{mo}$ & $\begin{array}{c}\text { Difference } \\
95 \% \mathrm{CI}\end{array}$ & $\begin{array}{c}\mathrm{p}- \\
\text { value }\end{array}$ & $\begin{array}{c}\text { Difference } \\
95 \% \mathrm{CI}\end{array}$ & $\begin{array}{c}\mathrm{p}- \\
\text { value }\end{array}$ \\
\hline $\begin{array}{l}\text { SBP AOBP } \\
(\mathrm{mmHg})^{\mathrm{d}}\end{array}$ & $\begin{array}{c}136 \\
(2.07)\end{array}$ & $\begin{array}{c}128 \\
(2.23)\end{array}$ & $\begin{array}{c}130 \\
(2.62)\end{array}$ & $\begin{array}{c}135 \\
(2.05)\end{array}$ & $\begin{array}{c}135 \\
(2.16)\end{array}$ & $\begin{array}{c}134 \\
(2.38)\end{array}$ & $\begin{array}{c}-7.49 \\
(-13.76 \text { to } \\
-1.22)^{\mathrm{C}} \\
\end{array}$ & 0.019 & $\begin{array}{c}-3.27 \\
(-10.18 \text { to } \\
3.65)^{\mathrm{C}} \\
\end{array}$ & 0.353 \\
\hline $\begin{array}{l}\text { SBP in } 24 \\
\text { hours } \\
\text { (mmHg) } \\
\text { ABPM }^{\mathrm{m}}\end{array}$ & $\begin{array}{c}125 \\
(1.41)\end{array}$ & $\begin{array}{c}122 \\
(1.55)\end{array}$ & $\begin{array}{c}122 \\
(1.80)\end{array}$ & $\begin{array}{c}123 \\
(1.39)\end{array}$ & $\begin{array}{c}124 \\
(1.50)\end{array}$ & $\begin{array}{c}121 \\
(1.67)\end{array}$ & $\begin{array}{c}-4.58 \\
(-7.79 \text { to } \\
-1.37)^{C}\end{array}$ & 0.005 & $\begin{array}{c}-0.90 \\
(-4.43 \text { to } \\
2.63)^{\mathrm{C}}\end{array}$ & 0.616 \\
\hline
\end{tabular}

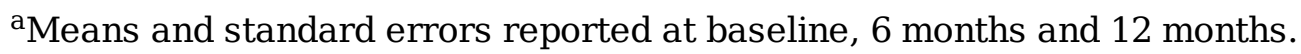

${ }^{b}$ Analysis generalized estimating equations (GEE) for repeated measures with an unstructured correlation matrix.

${ }^{\mathrm{C}}$ Analysis linear marginal model with an exchangeable correlation matrix for repeated measures.

${ }^{\mathrm{d}}$ Systolic blood pressure measured as automated office blood pressure (AOBP).

eSystolic blood pressure in $24 \mathrm{~h}$ in participants with more than $70 \%$ correct measurements in ambulatory blood pressure monitoring $(\mathrm{ABPM})$.

Abbreviations: $\mathrm{SE}=$ Standard error; mo=Months; $\mathrm{SBP}=$ Systolic blood pressure; $\mathrm{AMBP}=\mathrm{Ambulatory}$ blood pressure monitoring; HbA1c=Glycated hemoglobin; $\mathrm{AOBP}=$ Automated office blood pressure.

\section{Figures}




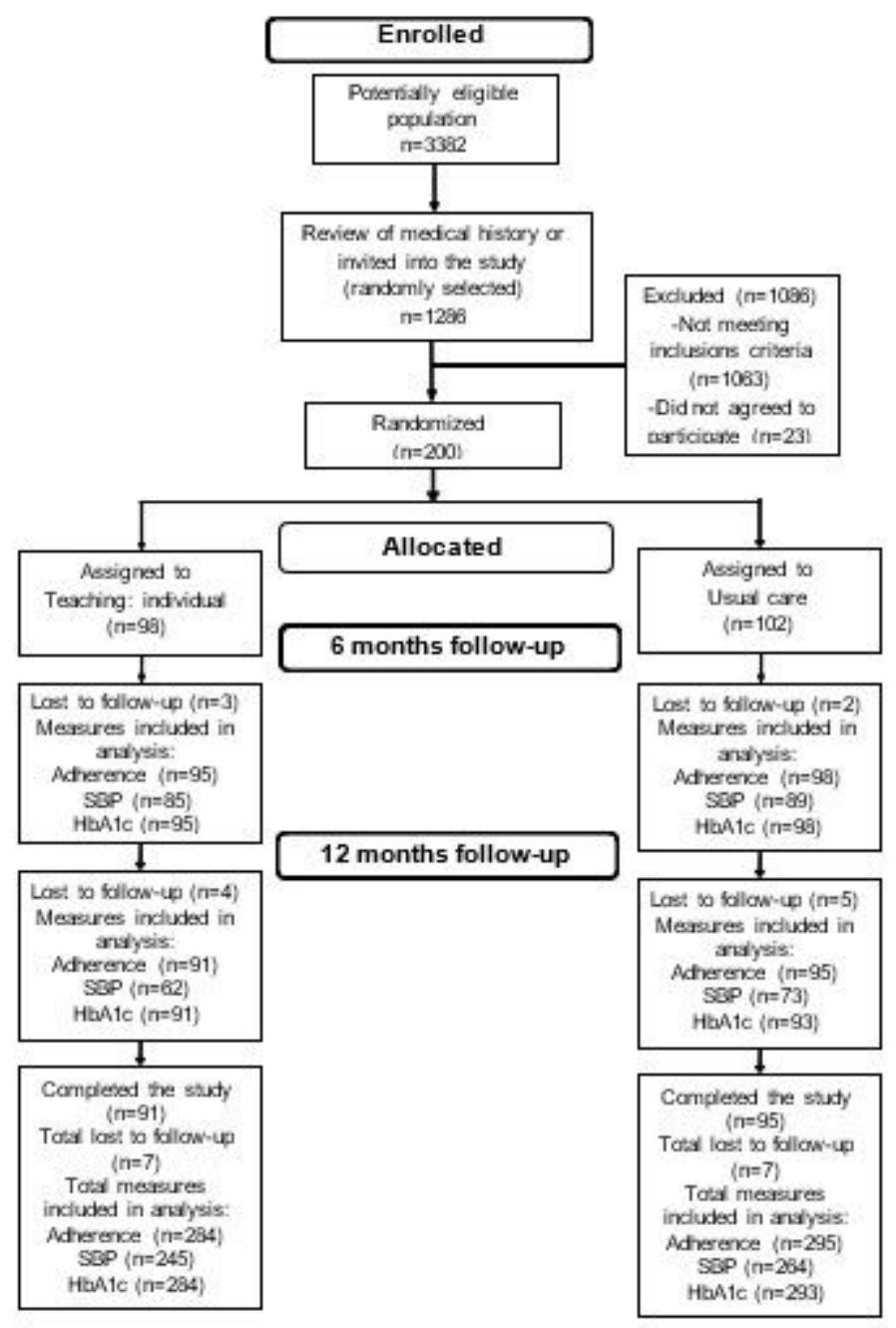

\section{Figure 1}

CONSORT flowchart showing the flow of participants throughout the trial. Abbreviations: SBP=Systolic blood pressure; HbA1c=Glycated hemoglobin.
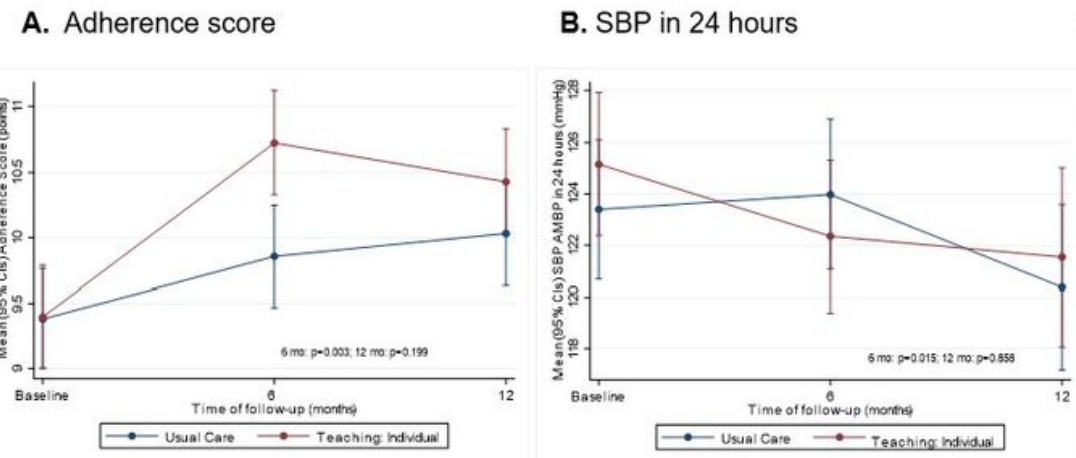

C. Glycated hemoglobin

Figure 2. Change in mean adherence, SBP and $\mathrm{HbA} 1 \mathrm{c}$ for the Teaching: Individual and Usual Care groups.

\section{Figure 2}


Change in mean adherence, SBP and HbA1c for the Teaching: Individual and Usual Care groups.

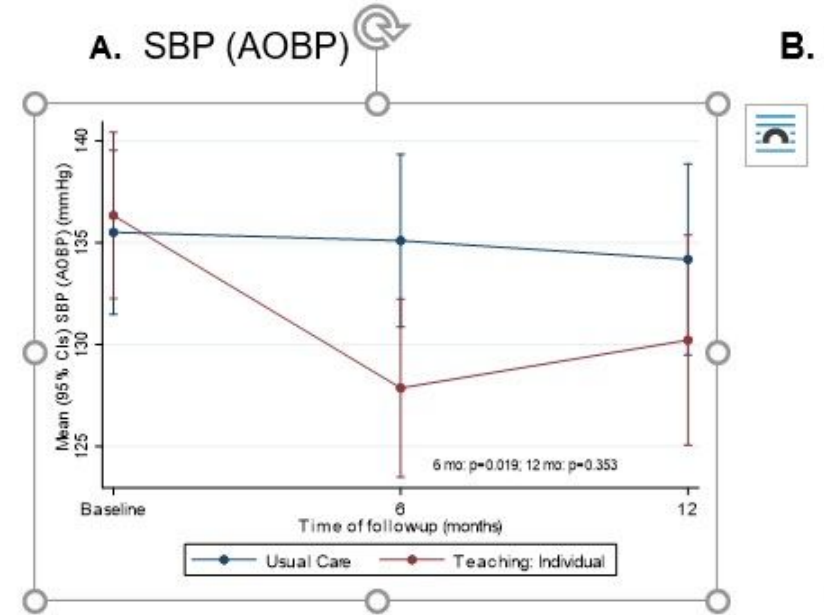

B. SBP in $24 \mathrm{~h}$ (ABPM $\geq 70 \%$ correct measurements)

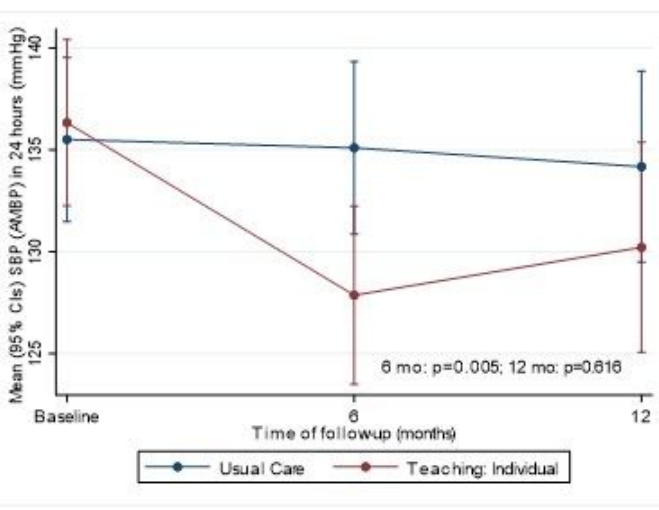

Figure 3. Change in mean SBP (AOBP and ABPM) for the Teaching: Individual and Usual Care groups.

\section{Figure 3}

Change in mean SBP (AOBP and ABPM) for the Teaching: Individual and Usual Care groups.

\section{Supplementary Files}

This is a list of supplementary files associated with this preprint. Click to download.

- CONSORT2010Checklist.docTeachingIndividual.pdf 